\title{
Malaria Risks Related to Poor Practices in the Use of Mosquito Bite Control Tools During The Cold and Hot Seasons
}

André Sominahouin ( $\nabla$ andrsominahouin@yahoo.fr )

Centre de Recherche Entomologique de Cotonou/ Ministère de la santé

Fortuné Dagnon

USAID

Gil Padonou

CREC

Rock Aikpon

CREC

Ludovic N'tcha

CREC

Bruno Akinro

CREC

Albert Salako

CREC

Fiacre Agossa

CREC

Dina Gbenou

CREC

Esdras Odjo

CREC

Christophe Houssou

FASHS

Martin Akogbeto

CREC

\section{Research}

Keywords: Malaria, Behaviors, Sleeping, Households, IRS, Mosquitoes, Benin

Posted Date: September 25th, 2020

DOl: https://doi.org/10.21203/rs.3.rs-38144/v2 
License: (c) (i) This work is licensed under a Creative Commons Attribution 4.0 International License. Read Full License 


\section{Abstract}

\section{Background:}

It is generally accepted that one of the reasons for the declining effectiveness of vector control tools (LLINs, IRS) is the misuse of these tools. Some people sleep outside while the walls of houses are treated with insecticide to protect people from mosquito bites.

\section{Methods:}

To check whether communities that misuse these tools are more exposed to malaria, we used the technique of direct and participatory observation of sleeping habits and we clocked every $30 \mathrm{~min}$, the activities and positions of the communities from $7 \mathrm{pm}$ to $7 \mathrm{am}$. The survey was conducted in 3 departments Northern Benin. These were mainly treatments related to variance analysis and descriptive statistics. Softwares used included SPSS 21, SAS 9.2 and Arcgis 10.4.

\section{Results:}

The study shows that $95 \%$ of the villages population included in the study stay in their rooms from 7:00 pm to 7:00 am, and only $5 \%$ of household members are outdoors during same time intervals during the harmattan season. On the other hand, during hot weather, there are more households outdoors (37\%). Less than $20 \%$ of household members are outside their rooms during the harmattan season. This number decreases gradually until 10:00 pm when all of them are inside their rooms.

Student Newman Keuls test shows that the household members being inside or outside their rooms does not depend on the urbanization situation of the village, but rather on the period.

$65 \%$ exposed to mosquito bites gave irritation as the main reason for their behavior and $15 \%$ because of heat and lack of space. Overall, because of household member mobility and malaria vector behaviors, human exposure to An. gambiae was higher outside than inside, despite all the observed food preferences in the vectors.

\section{Conclusion:}

To curtail residual malaria transmission, it must be prioritized to raise awareness in the best use of the tools and provide other complementary control tools for use outside the home.

\section{Background}

Malaria is the most significant disease burden in the North Benin departments with 128,261 disease cases in Alibori, 166,385 in Atacora and 159,083 in Donga [1]. Malaria transmission is higher during the rainy season, typically from May to October in the same part of the country [2]. Thus, the National Malaria Control Program (NMCP), in its strategic plan to fight against malaria has put a particular emphasis on 
vector control which is based on two main complementary interventions: the promotion of Long-Lasting Insecticide-treated Nets (LLINs) use and Indoor Residual Spraying (IRS) [3].

In 2014, 1,290,000 people were protected by indoor residual spraying during campaigns organized by the Ministry of Health in Benin. Beside this, there were the free distribution of 5 million impregnated mosquito nets, and the prevention of intermittent malaria during pregnancy for more than 1 million pregnant women [4]. From 2012 to 2016, IRS coverage rates were well above those registered (85\%). From 652,777 in 2012 , the number of protected population in the Atacora department by the IRS reached 858,113 in 2016 [5].

In 2017, 6,695,750 long-lasting impregnated mosquito nets were distributed free of charge to fight malaria. In addition, there was the implementation of IRS as a complementary strategy to the prevention and elimination of malaria in selected eligible municipalities in Alibori and Donga departments [6].

In Benin, the incidence of malaria and case-fatality rate dropped from 17-14.6\%, and from 1.4 per 1,000 to 0.8 per 1,000 between 2012 and 2016 , respectively [7].

Despite these results, malaria remains a real public health issue and the leading cause of consultation and hospitalization (34\% of reasons) in Benin, especially among children under five and pregnant women. Thus, one might ask why the incidence of malaria transmission in the country remains high after decades of vector control and what is really to be done?

In fact, anopheles are Northern Benin nocturnal species. Also, populations prefer to stay out at night for various occupations, which prevents them from enjoying the protection offered by the current vector control tools during that period of the day. Nighttime activities, including outdoor sleep, may increase exposure to infective Anopheles bites [8].

The context of our study gives rise to two main questions: What are the nighttime malaria-contracting risk behaviors observed in populations despite the massive presence of vector control tools?

At what periods of the night do we observe communities that are the most vulnerable to infective Anopheles bites?

Findings from the study might also inform communication design of potential behavior change or other interventions to reduce the risk of infection from outdoor malaria.

\section{Methods}

\section{Presentation of the study zone}

Benin is one of the 17 countries receiving funding under the PMI/AIRS project. The figure below is a map showing the prospected sites (Figure 1). 
The survey was conducted in 3 departments (Alibori and Donga under IRS and Atacora after IRS). Two communes were selected per department and two sites were visited per commune. One site was selected from the central part of the commune and one at the periphery. In total, 96 households were followed up:

- 32 households in Natitingou and Boukoumbé districts in the NBT health zone after end of IRS;

- 32 households in Gogounou and Kandi districts in KGS health zone under IRS;

- 32 households in Djougou and Copargo in the DCO health zone under IRS.

\section{Criteria for selecting households}

Table I shows villages selected per commune. In each village, eight (08) households were selected according to the following criteria:

$\sqrt{ }$ The households must comprise at least 05 people (adults and children or pregnant women);

$\sqrt{ }$ The households must have been treated during the last Indoor Residual Spraying (IRS) campaign if they are located in Alibori and Donga departments;

$\sqrt{ }$ The households must have at least one LLIN;

$\sqrt{ }$ The households must have a member or parent to train and use as an pollster;

$\sqrt{ }$ The households must be distributed throughout the territory of the site and at a distance of at least 80 meters from each other. 
Table 1

Study sites

\begin{tabular}{|c|c|c|c|c|}
\hline Zones & Departments & Communes & Urbanization & Villages \\
\hline \multirow[t]{8}{*}{ IRS Zone } & \multirow[t]{4}{*}{ Donga } & \multirow[t]{2}{*}{ Djougou } & Urban Zone & Zountori \\
\hline & & & Peripheral zone & Barienou \\
\hline & & \multirow[t]{2}{*}{ Copargo } & Urban Zone & Kparakouna \\
\hline & & & Peripheral zone & Kataban \\
\hline & \multirow[t]{4}{*}{ Alibori } & \multirow[t]{2}{*}{ Kandi } & Urban Zone & Kossarou \\
\hline & & & Peripheral zone & Sonsoro \\
\hline & & \multirow[t]{2}{*}{ Gogounou } & Urban Zone & Batansoue \\
\hline & & & Peripheral zone & Gounarou \\
\hline \multirow[t]{4}{*}{ Non-IRS Zone } & \multirow[t]{4}{*}{ Atacora } & \multirow[t]{2}{*}{ Natitingou } & Urban Zone & Boriyoure \\
\hline & & & Peripheral zone & Kotopounga \\
\hline & & \multirow[t]{2}{*}{ Boukombé } & Urban Zone & Koutchagou \\
\hline & & & Peripheral zone & Koussoucouingou \\
\hline
\end{tabular}

\section{Data collection techniques and tools}

\section{Direct observations all night, from 7:00 pm to 7:00 am}

All outdoor and indoor activities observed were timed every 30 minutes to follow each member throughout the night from 7:00 pm to 7:00 am. The goal was to identify the practices of each member of the family favoring contact with mosquitoes at night. The activities included: cooking, watching television, listening to the radio, having some rest, working at home, working with a laptop, phoning, listening to music, eating, sleeping without the mosquito net, sleeping under the mosquito net, chatting with someone, playing, praying, washing dishes, taking a bath. A form was developed to point out each member's activity and specify where each activity took place (indoors or outdoors) from 7:00 pm to 7:00 based on the form of the protocol. (Figure 2).

\section{Qualitatives data}

A qualitative questionnaire was shared with adult household members to have their perception of the fight tools and the factors preventing the use of LLINs. 


\section{Data processing hardware and software}

Data processing was made possible by the use of some softwares classified in three categories: GIS and Spatial Analysis, Remote Sensing/Digital Image Processing, Data Analysis/Modeling and GPS Management.

- GIS and spatial analysis software was used to apply spatial processing to data: geometric transformation, projection, interpolation, and estimation. The software used was: Arcgis 10.3 with Spatial Analyst and Geostatiscal Analyst extensions of ESRI.

- Statistical data processing/modeling software was used for data analysis. These were mainly treatments related to variance analysis and descriptive statistics. Softwares used included SPSS 21 , SAS 9.2 .

- GPS software allowed us to download the coordinates of the surveyed localities. The GPS track maker, Odilon Ferreira Junior, and DNR Garming softwares also helped.

This study looked at the behaviors of the populations who were in inadequacy with the fight tools in the IRS and non-IRS communes. This activity was intended to give information about communication design of potential behavior change or other interventions to reduce the risk of infection from external malaria.

We thus collected quantitative and qualitative data through direct and participative observation of activities and locations every 30 minutes from 7:00 pm to 7:00 am for each household member included in the study. The activities included: cooking, watching television, listening to the radio, having some rest, working at home, working with a laptop, phoning, listening to music, eating, sleeping without the mosquito net, sleeping under the mosquito net, chatting with someone, playing, praying, washing dishes, taking a bath.

\section{Capturing mosquitoes on humans}

In each of the communes, a central and a peripheral zone were chosen. Monthly catches of aggressive mosquitoes per hour were taken in both areas using hemolysis tubes from $7 \mathrm{pm}$ to $7 \mathrm{am}$ on volunteer human subjects who had previously given their favourable consent for the activity to take place. Two nights of mosquito collection were organized per month before, during and after the cessation of IRS. These catches were made from january to may 2018. In each commune, two boxes were chosen per zone for mosquito collection. The recorded data allowed to evaluate the aggressive density.

\section{Results}

\section{Distribution of the population according to their positions from 7:00 pm to 7:00 am}


This study looked at the position of household members in selected villages during the harmattan and hot weather seasons. The results of household members' distribution are shown in Figure 3.

On the one hand, Figure 3 shows that $95 \%$ of the village population included in the study stay in their rooms from 7:00 pm to 7:00 am, and only 5\% of household members are outdoors during same time intervals during the harmattan season. On the other hand, during hot weather, there are more households outdoors (37\%) as shown in Figure 3. Most households, regardless of their position, don't sleep under mosquito nets and are exposed to mosquito bites as shown in Figures 4.

\section{Breakdown of the position of household members by time interval during the harmattan and hot weather seasons}

In order to determine the time intervals during which all household members are inside their rooms, the position of each of them household member's location was observed every $30 \mathrm{~min}$, the results of which are illustrated by Figures $5 \mathrm{a}$ and $5 \mathrm{~b}$.

According to Figure $5 \mathrm{a}$, from 7:00 pm to $7: 30 \mathrm{pm}$, less than $20 \%$ of household members are outside their rooms during the harmattan season. This number decreases gradually until 10:00 pm when all of them are inside their rooms. From 5:30 am, household members begin to step out of their rooms until 7:00 am when $10 \%$ of the population is outside the rooms. Unlike Figure $5 \mathrm{~b}$, the latter shows that during the hot weather season, the majority of household members stay outside from 7:00 pm to 10:00 pm, and begin to enter their rooms gradually only from 10:30 pm. However, during the whole night there are always people outside, carrying out various activities. The latter shows that during the hot weather season, the majority of household members stay outside from 7:00 pm to 10:00 pm, and begin to enter their rooms gradually only from 10:30 pm. However, during the whole night there are always people outside, carrying out various activities.

\section{Influence of the season and the urbanization situation of villages on the position of household members}

In this study, the factors determining the position of household members (outside or inside the rooms) of North Benin departments from 7:00 pm to 7:00 am, the time of appearance of malaria Anopheles vectors, were investigated. Thus, an analysis of the two-factor bias variances on the frequency of the position of household members according to the season and their residence areas (peripheral or central village) was carried out (Table 2). 
Table 2

Analysis results of variance on the position of household members according to the season and their residence area

\begin{tabular}{|llllll|}
\hline Sources & $\mathrm{df}$ & \multicolumn{4}{c|}{ Value of Ficher } \\
\cline { 3 - 6 } & & Outside & $\mathrm{p}$-value & Inside & $\mathrm{p}$-value \\
\hline Zones & 1 & 0.26 & $\mathrm{p}>>5 \%$ & 2.46 & $\mathrm{p}>>5 \%$ \\
\hline period & 2 & 70.70 & $\mathrm{p}<<1 \%$ & 18.53 & $\mathrm{p}<<1 \%$ \\
\hline Zones*period & 2 & 0.29 & $\mathrm{p}>>5 \%$ & 0.46 & $\mathrm{p}>>5 \%$ \\
\hline
\end{tabular}

Table 2 shows that there is no significant difference $(p>0.05)$ between the position frequency of household members and the type of village they live in. However, the analysis of the variances shows a highly significant difference between the period and the position of household members $(p<0.001)$. This analysis shows that the household members being inside or outside their rooms does not depend on the urbanization situation of the village, but rather on the period. Figure 10 shows the results of the Student Newman Keuls test.

\section{Influence of the IRS or non-IRS status of the areas on the position of household members}

In this study, the influence of study areas (IRS or non-IRS) on the position (outside or inside the rooms) of household members was verified. An analysis of variances by one factor on the number of household members operating from 7:00 pm to 7:00 am outside or inside their rooms according to IRS or non-IRS status of the areas, made it possible to determine influence of household members fear of mosquito bites. Table 3 illustrates the results of the analysis.

The analysis in Table 3 shows that the effect has a highly significant influence (Prob $<0.0001$ ) on the frequency of household members who remain outdoor their rooms from 7:00 pm to 8:00 pm, depending on whether they are in an IRS or non-IRS area. In addition, the analysis of the variances shows no significant difference between the IRS and non-IRS status of the areas and the frequency of household members staying indoor their rooms. From the foregoing, it can be observed that the action of the IRS conditions the choice of the outdoor position in the North Benin villages.

Table 3

Analysis results of variance carried out on the position of household members according to the IRS or non-IRS status of the areas.

\begin{tabular}{|llllll|}
\hline Source & $\mathrm{df}$ & \multicolumn{4}{|c|}{ Value of Ficher } \\
Zone & 1 & Outdoor & $\mathrm{p}$-value & Indoor & $\mathrm{p}$-value \\
\cline { 3 - 6 } & & 4.12 & $\mathrm{p}<<1 \%$ & $0.7 \mathrm{~ns}$ & $\mathrm{p}>>5 \%$ \\
\hline
\end{tabular}


Student-Newman-Keuls (SNK) tests performed on the difference in the frequency of household members staying outdoor their rooms were used to determine the area in which more household members were found outside from 7:00 pm to 7:00 am. The results of these tests are shown in Figure 6.

The analysis in Figure 7 shows that there are more household members spending their time outside their rooms in non-IRS areas than in IRS areas. From this analysis, it can be noted that in villages where indoor spraying is in progress, household members are more likely to protect themselves against mosquito bites by performing their night activities inside their sprayed rooms than in other villages where the spraying action is no longer effective. From all of the above, it can be noted that household members in the North Benin departments recognize the effectiveness of IRS by staying inside their rooms from 7:00 pm to 7:00 am when the effect of spraying is still active.

\section{Variation of household members inside under the net and outside without the bed net as a function of density of An.gambiae measured at different times of the night.}

- During the hot season

Behavioural activities of humans and An. gambiae, a vector of malaria outside households in the absence of the net, were compared with those of residents inside households with nets at different night time intervals throughout the warm period (Figure 8). At dusk, high mobility activity both outside and inside households showed a low rate of mosquito aggressiveness outside and inside households. The decrease in this mobility from 9pm onwards, characterised by rest, eating, studying, following information on television and radio, sleeping without or with mosquito nets, etc., caused a sudden increase in $A n$. gambiae's aggressiveness. This increase is more noticeable outside households than within households. The aggressiveness of An. gambiae mosquitoes reached its threshold after 1.am in the morning. Despite the low level of outdoor activity at this time of day, aggressiveness is still higher than indoors with an average difference of 0.87 bites per man per hour. Then, this rate of stings gradually decreased as mobility activities were resumed.

From this figure, there is a high level of human activity in households from $7 \mathrm{pm}$ to $10.30 \mathrm{pm}$ and the resumption of activities from $4 \mathrm{am}$ onwards. From $22 \mathrm{~h} 30$ to $4 \mathrm{~h}$ in the morning is the period dedicated to rest in the mosquito nets for most of the inhabitants. An gambiae's aggressiveness outside and inside households increased slightly during the first two hours after $7 \mathrm{pm}$ and then significantly until $1 \mathrm{am}$ when it is at its peak before gradually decreasing until 7am. Throughout the observation period, there was greater aggression outside households without nets than inside.

\section{- During the harmattan season}


During the harmattan, the average density of An. gambiae mosquitoes was much higher inside households than outside. This behaviour of malaria-carrying mosquitoes has shown a maximum level of aggressiveness within households. This aggressiveness of An. gambiae in households at dusk is much higher than that observed outside households with a large difference of about 0.55 bites (Figure 9). Then, aggressiveness on the inside first dropped, while on the outside, there is a slight increase for about an hour before it becomes uniform with the inside. At night, rates of aggression inside and outside households oscillate around 0.02 to 0.2 bites with a small increase inside compared to outside. The majority of household members protect themselves under the net from $11 \mathrm{pm}$ onwards. From dawn onwards, aggressiveness indoors has increased exponentially inside and slightly outside households.

\section{Causes of outdoor biting exposure}

Since exposure to mosquito bites is related to the position of household members in relation to their sprayed rooms, this study investigated the causes of outdoor biting exposure. The results from this study are illustrated in Figure 10.

The analysis of this figure shows that $65 \%$ of household members exposed to mosquito bites gave irritation as the main reason for their behavior. $15 \%$ of them are exposed to biting because of heat and lack of space.

\section{Discussions}

This study shows biting exposure behaviors of household members during harmattan and heat periods. These two seasons are characterized by different climatic factors and have impacts on the sleep behaviors of the populations and the availability of malaria vectors in North-Benin departments.

As a matter of fact, $95 \%$ of village household members included in the study stay inside their rooms from 7:00 pm to 7:00 am, and only 5\% of them are outside at same time frame during the harmattan season. Thus at the beginning of the evening, that is to say from 7:00 pm to $7: 30 \mathrm{pm}$, less than $20 \%$ of the household members are outside their rooms during the harmattan season. This number decreases gradually until 10:00 pm when all of them are inside their rooms. In the hot weather season, on the other hand, more household members stay outside their rooms. In addition, the majority of the household members stay outside their rooms from 7:00 pm to 10:00 pm, and start stepping into their rooms gradually only from 10:30 pm.

In addition, most household members, regardless of their position, do not sleep under mosquito nets and are exposed to mosquito bites. This is mainly due to the phenomenon of heat (high room temperature) during this time of the year (hot weather season), which forces people to stay much more outside their rooms even late at night and sometimes until dusk. 
In addition, the influence of the fear of biting exposure based on the IRS or non-IRS status of the areas has shown a highly significant influence (Prob $<0.0001$ ) on outdoor biting exposure frequency from 7:00 $\mathrm{pm}$ to 7:00 am and has no effect on the indoor frequency. It can therefore be maintained that the action of the IRS conditions the choice of outdoor biting exposure position in the study area.

Our results are similar to those of April et al. which showed that outdoor biting exposure was frequently encountered at both study sites during the night [9]. Although household members used mosquito nets as an important tool for the prevention of malaria, the LLIN use observed was low for both biting exposures (indoor and outdoor). Outdoor sleep and other nighttime activities have been broad and could significantly increase the risk of malaria. These results suggest that inward-oriented control measures such as LLINs and IRS are not enough to eliminate malaria in children.Dunn et al. found that changing sleep patterns in response to socio-cultural events and livelihood activities in southern Tanzania had an impact on the use of LLINs [10]. In addition, Matowo et al., also in southern Tanzania, described nighttime and dawn activities comparable to those observed in this study and demonstrated their overlap with An. Arabiensis and An.funestus bite motives [11]. Similarly, a study in Uganda identified outdoor biting exposure barriers, including social, logistical and access issues. In line with this study, attendance at funeral services was a significant limitation to LLIN use [12].Our results confirm those of Moshi et al. in 2017 who pointed out that participants were frequently bitten by mosquitoes during the evening when they were outdoors, compared to when they were indoors [13]. Most participants stay outdoors in the early evening to do housework which are not possible indoors. The structure of the house, poor ventilation and warm weather conditions were the main reasons for outdoor biting exposure in the evening. Participants reported wearing long-sleeved clothes, trousers, using repellents, and burning cow dung and neem leaves to chase mosquitoes.

Overall, because of household member mobility and malaria vector behaviors, human exposure to $A n$. gambiae was higher outside than inside, despite all the observed food preferences in the vectors.

According to Gryseels, nighttime outdoor activities carried out by Cambodians, in a context where malaria vectors have at least one exophagic and exophilic behavior, increase the risk of outdoor biting and malaria transmission [14]. Complementary malaria control measures need to be developed for periods of outdoor activity during vector bite hours in northern Ghana and elsewhere [15].

\section{Conclusion}

This study confirms the presence of spatio-temporal heterogeneity in outdoor sleep and night activities in IRS and non-IRS areas. The spatial variance was stronger than temporal.

Whenever possible, studies should include research on anthropological behaviors to better understand nighttime activities and sleep patterns with respect to malaria risk. In the future, entomological studies should include parallel research on human behavior. A standardized approach will be used to monitor human-vector interaction and gaps in protection provided by LLINs, as well as vector control interventions, over time and in all settings. This information is essential for the strategic targeting of 
existing tools, effective interventions for social change and the deployment of appropriate complementary prevention tools.

\section{Declarations}

\section{Competing interests}

The authors declare that they have no competing interests.

\section{Author Contributions}

AS, FA, RA, LN and MCA designed the study. AS, GGP, FA and MCA participated in the design of the study. ASS, IA, SA, FA and AAS collected entomological data. RA, SA, FA and AAS carried out bioassays and laboratory analysis. DG and MCA drafted the manuscript. FA, AB, AS, FD and MCA critically revised the manuscript for intellectual content. All authors read and approved the final manuscript.

\section{Acknowledgment}

Field activities were funded by Centre de Recherche Entomologique de Cotonou (CREC) in Health Ministry. We thank the population of Cotonou for their kind collaboration.

\section{Ethics approval and consent to participate}

Permission was sought from households to perform collections in their rooms. In addition, community consent had been obtained beforehand in all the villages. The investigators gave their consent before participating in the study. They were also subjected to regular medical check-ups with preventive malaria treatment. They were all vaccinated against yellow fever. This study received the approval of the Ethical Institutional Committee of the Centre for Entomological Research of Cotonou (CREC), Ministry of Health.

\section{Consent for publication}

Not applicable.

\section{Availability of data and materials}

The data supporting the conclusions of this article are included within the article. The raw data used and/or analyzed in this study are available from the corresponding author upon reasonable request. 


\section{Funding}

This study was financially supported by the US President's Malaria Initiative (PMI) through the United States Agency for International Development (USAID) Africa Indoor Residual Spraying Project (AIRS).

\section{Authors' contributions}

AS, GGP, and MCA conceived the study. AS, ASS, FA and MCA participated in the design of the study. AS, RA, RO, FA and AAS collected sleeping data. AS, FA and ASS carried out survey and laboratory analysis. AS and MCA drafted the manuscript. FA, AS, RA, FD and MCA critically revised the manuscript for intellectual content. All authors read and approved the final manuscript.

\section{Author details}

${ }^{1}$ Centre de Recherche Entomologique de Cotonou (CREC), Cotonou, Bénin. ${ }^{2}$ Département de Géographie et Aménagement du Territoire de l'Université d'Abomey-Calavi, Benin. ${ }^{3}$ Faculté des Sciences et Techniques de I'Université d'Abomey Calavi, Benin. ${ }^{4}$ Programme National de Lutte contre le Paludisme (PNLP).

${ }^{5}$ Oranisation Mondiale de la Santé, Bénin. ${ }^{6}$ US President's Malaria Initiative, US Agency for International Development, Cotonou, Benin.

\section{References}

1. Ministère de la santé du Bénin-santé.info. Enquête Demographique de la Santé du Bénin. 2017-2018, 675. https://www.insae-bj.org/images/docs/insae-statistiques/enquetes recensements/EDS/20172018/1.Benin_EDSBV_Rapport_final.pdf

2. Martiny N, Dessay N, Yaka P, Toure O, Sultan B, Rebaudet S, et al. Le climat, un facteur de risque pour la santé en Afrique de l'Ouest. La Météorologie, Météo et Climat, 2012, pp.73-79.

ff10.4267/2042/48135ff. ffhal-00757107f.

3. OMS 2015, Méthodes de lutte antivectorielle de base. https://www.who.int/malaria/areas/vector_control/core_methods/fr/

4. USAID 2017-2021. P 196. Prévention et contrôle du paludisme pendant la grossesse.

5. ABP/IM/DKJ 2014. La performance de la pulvérisation intra domiciliaire pour lutter contre le paludisme en débat à Natitingou.

6. USAID 2013 Rapport sur la mise en œuvre du programme de lutte contre le paludisme au Burkina Faso Préparé par MCHIP/USAID en collaboration avec le Programme National de Lutte contre le Paludisme Mars 2013.

7. PNLP, MS-Bénin, 2012. l'annuaire des statistiques sanitaires du ministère de la santé en 2012. Analytical summary - Malaria. 
8. Monroe A, Asamoah O, Lam Y, Koenker H, Psychas P, Lynch M et al. Outdoor-sleeping and other nighttime activities in northern Ghana: implications for residual transmission and malaria prevention. Malaria Journal. 2015;14: 35

9. Cooke KMK, Kahindi SC, Oriango RM, Owaga C, Ayoma E, Mabuka D et al. .A bite before bed': exposure to malaria vectors outside the times of net use in the highlands of western. Malaria Journal. 2015; 14: 259

10. Monroe A, Mihayo K, Okumu F, Finda M, Moore S, Koenker $\mathrm{H}$ et al. Human behaviour and residual malaria transmission in Zanzibar: indings from in-depth interviews and direct observation of community events. Malaria journal. 2019; 18:220.

11. Dunn CE, Le Mare A, Makungu C. Malaria risk behaviours, socio-cultural practices and rural livelihoods in southern Tanzania: implications for bednet usage. . Soc Sci Med. 2011 Feb;72:3, 40817.

12. Monroe A, Harvey SA, Lam Y, Muhangi D, Loll D, Kabali AT et al. People will say that I am proud: a qualitative study of barriers to bed net use away from home in four Ugandan districts.. Malaria Journal 2014, 13:82 http://www.malariajournal.com/content/13/.

13. Moshi , Ngowo H, Msellemu AD, Madumla EP. , Okumu FO. , Coetzee M et al. Published online 2017 Jul 4. Community perceptions on outdoor malaria transmission in Kilombero Valley, Southern Tanzania. Malaria Journal. 2017; 16: 274.

14. Trung HD, Bortel WV, Sochantha T, Keokenchanh K, Briët OJ, Coosemans M. Behavioural heterogeneity of Anopheles species in ecologically different localities in Southeast Asia: A challenge for vector control. Tropical Medicine \& International Health 10(3):251-62 · April 2005 with 43 Reads.

15. Monicah M. Mburu. Thesis 2019. Indoor and outdoor biting behaviour of malaria vectors and the potential risk factors that enhance malaria in southern Malawi. 204p.

\section{Figures}




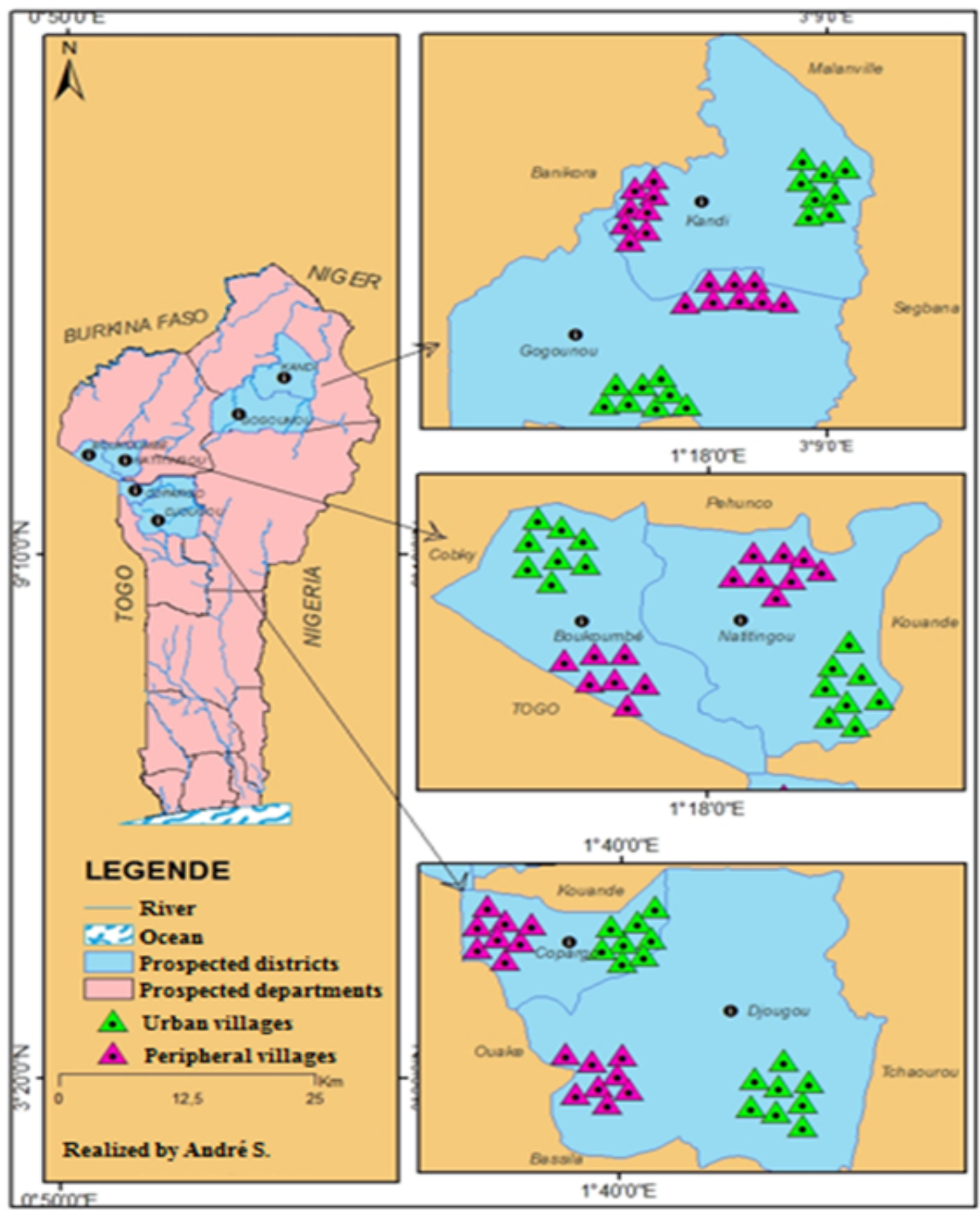

Figure 1

Map of the study area showing selected households 


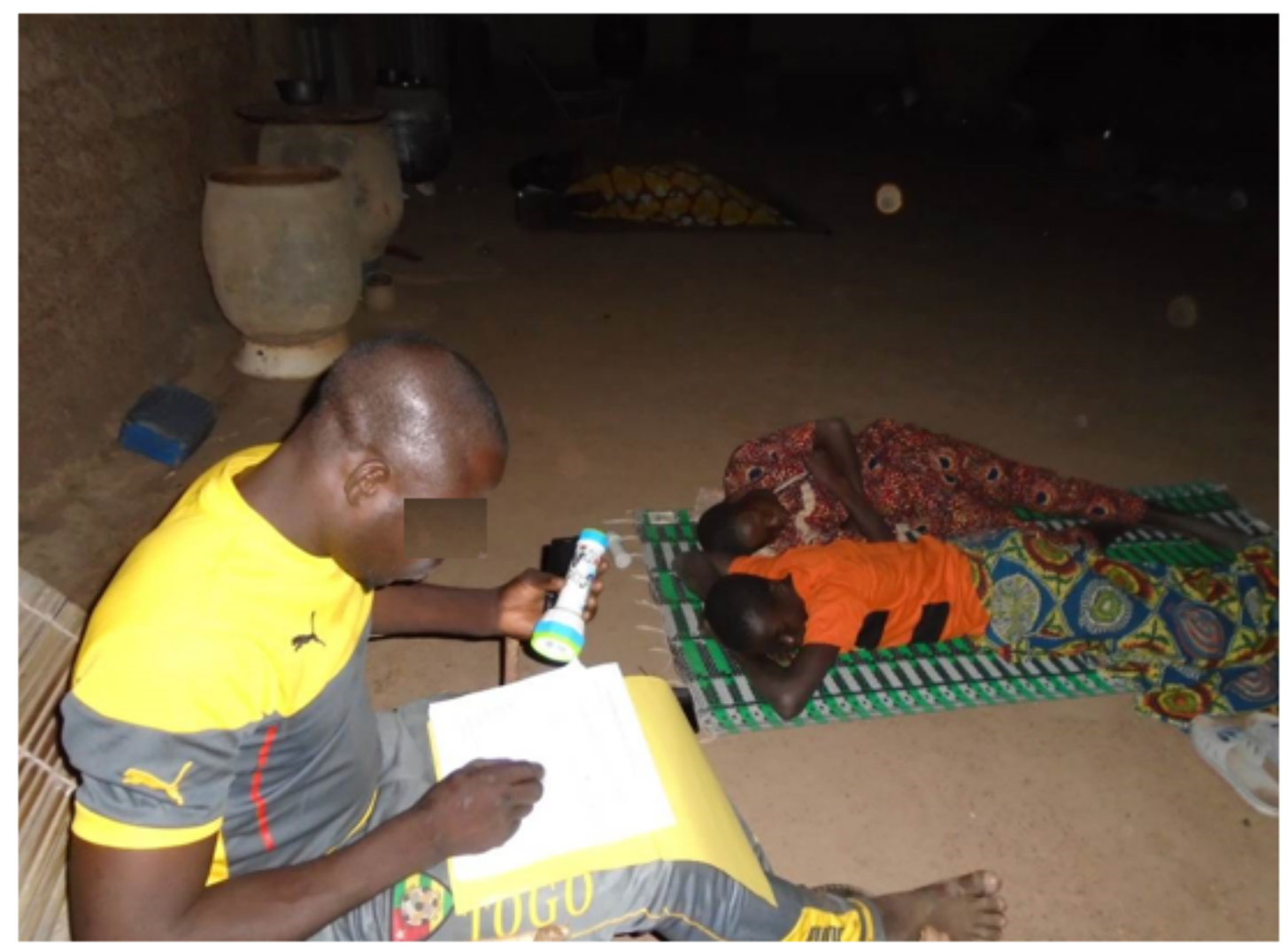

Figure 2

Pollster marking the observation sheet of household members already sleeping from 9:00 pm during the hot weather season in Kataban, Copargo

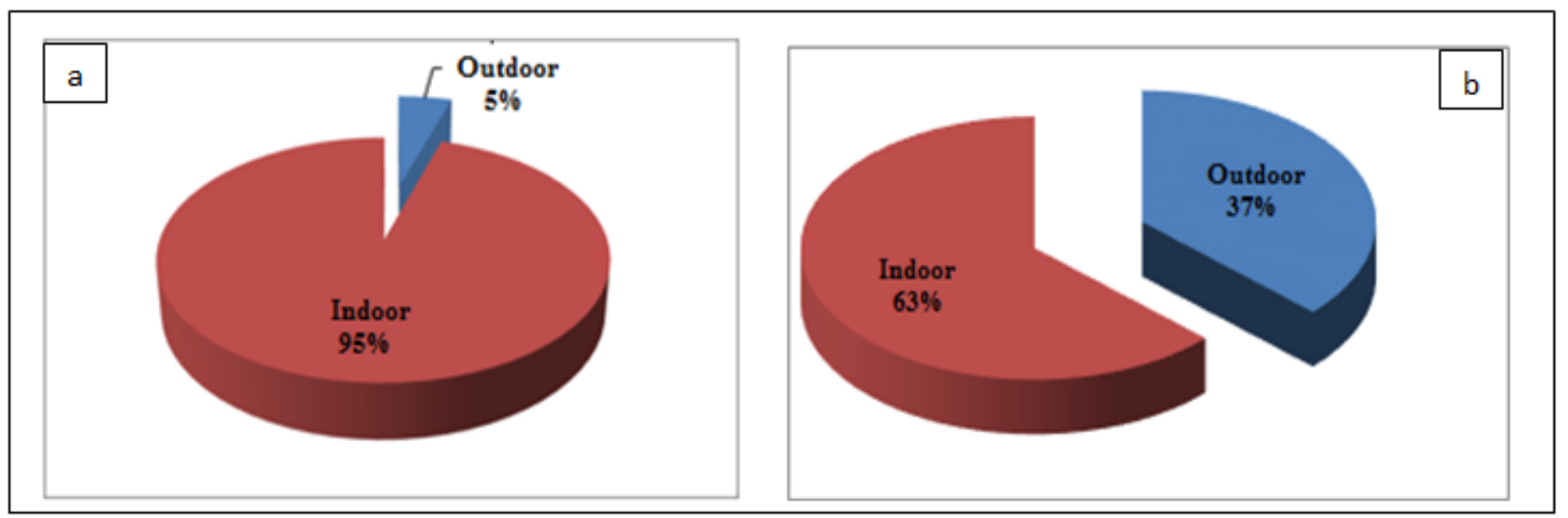

Figure 3

Distribution of the population according to their position from 7:00 pm to 7:00 am during the harmattan season (a) and during the hot weather season (b) 


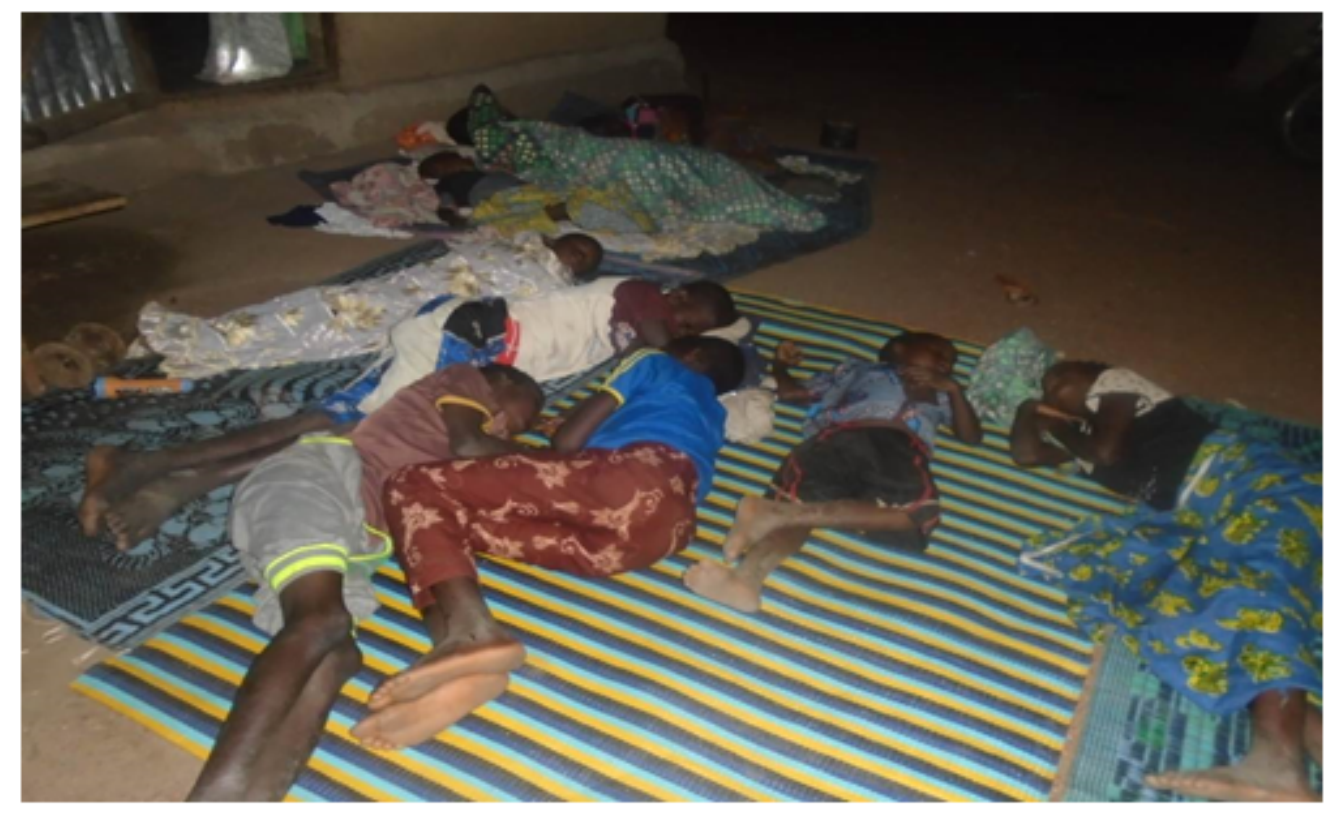

\section{Figure 4}

Nighttime behavior of household members sleeping outside their rooms without LLIN, March 2018 in Kataban
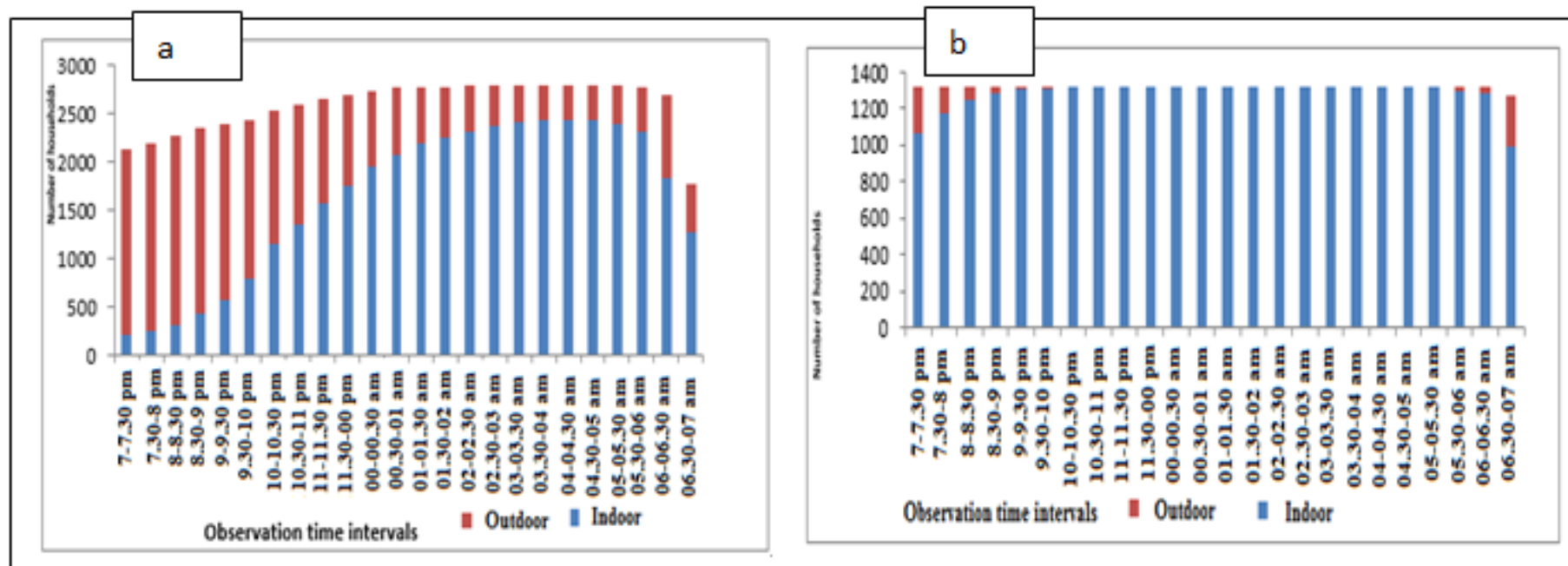

\section{Figure 5}

Position of household members according to observation time frames during hot season (a) and harmattan season (b) 


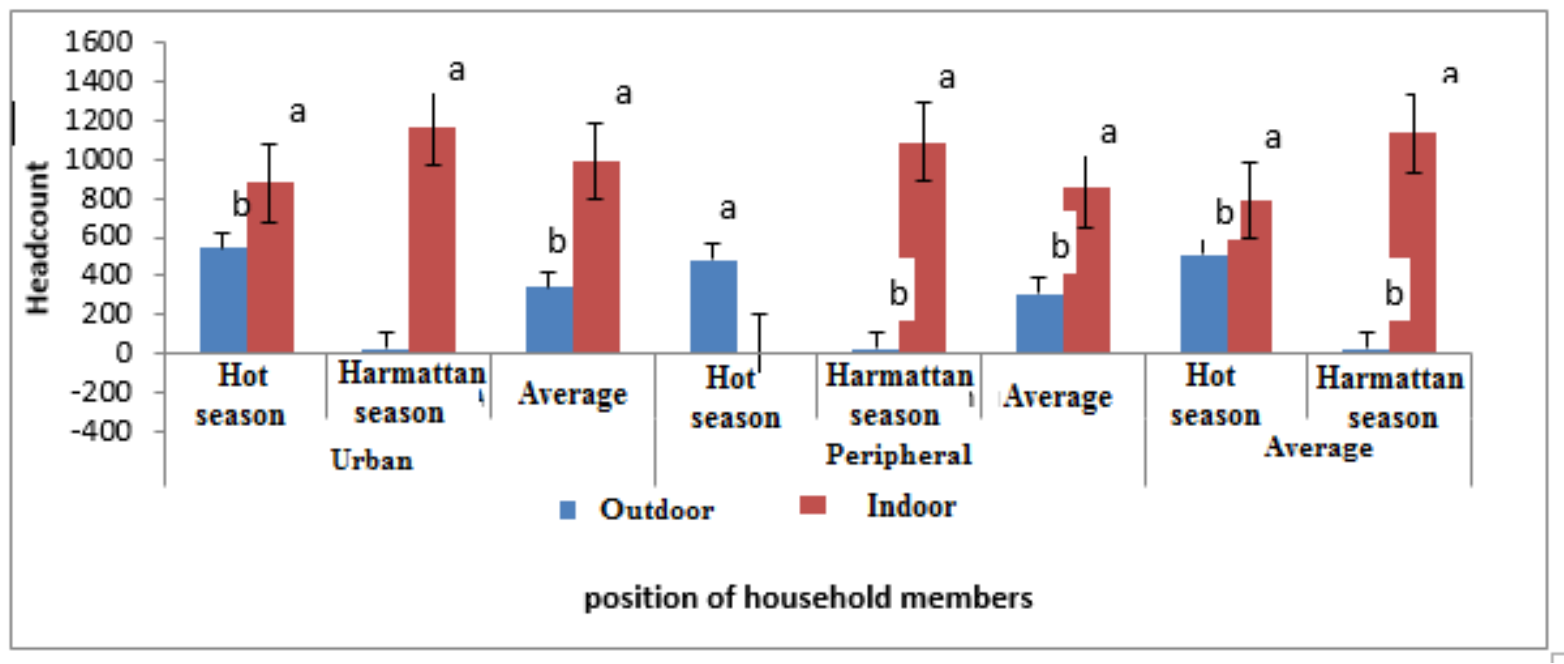

\section{Figure 6}

Error bars represent standard errors. Bars with the same letter are not significantly different according to the Student Newman Keuls test $(P>0.05)$. Position of household members from 7:00 pm to 7:00 am depending on the period and the urbanization of the village

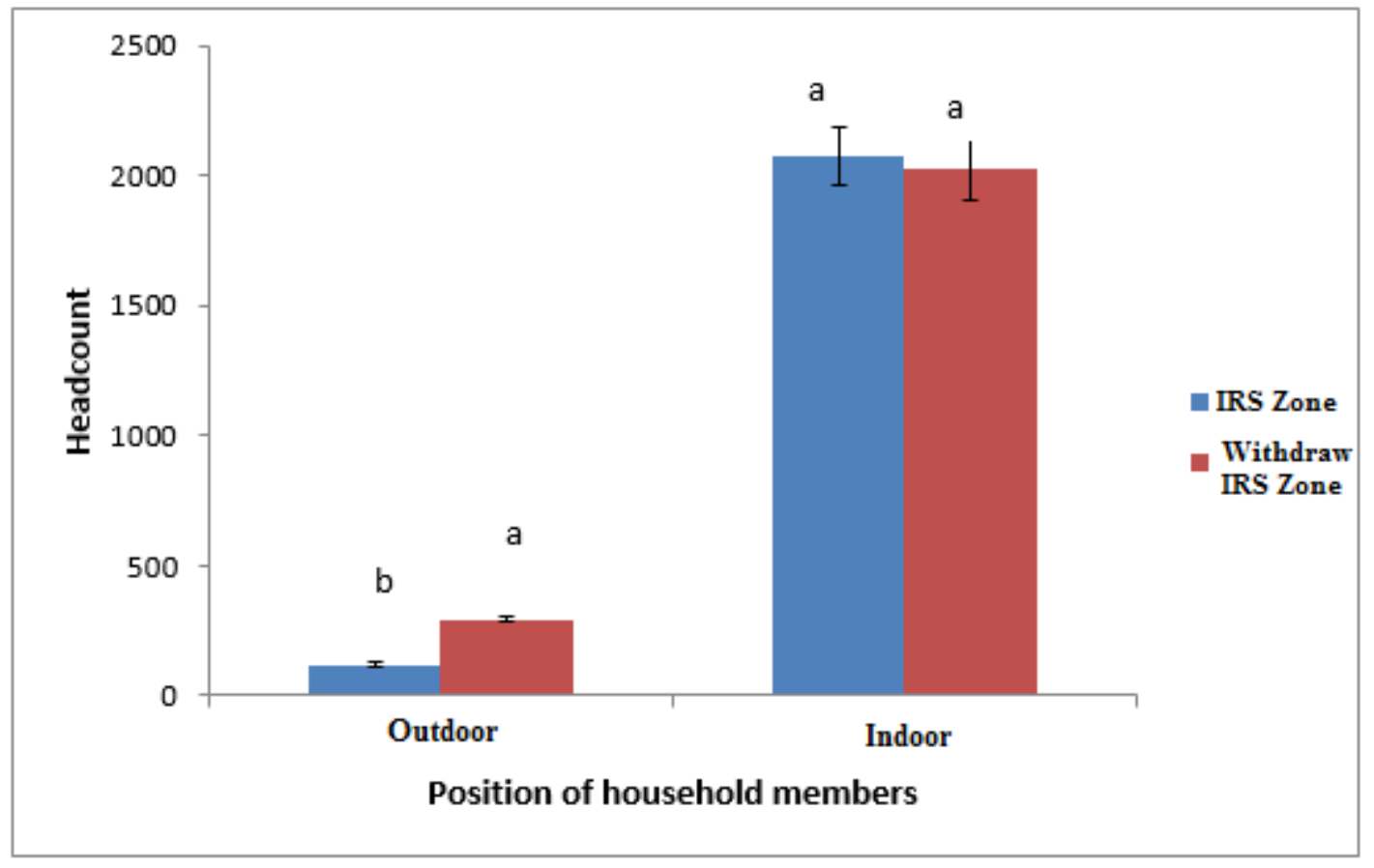

\section{Figure 7}

Error bars represent standard errors. Bars with the same letter are not significantly different according to the Student Newman Keuls test $(P>0.05)$.> Position of household members from 7:00 pm to 7:00 am, depending on the IRS or non-IRS status of the area 


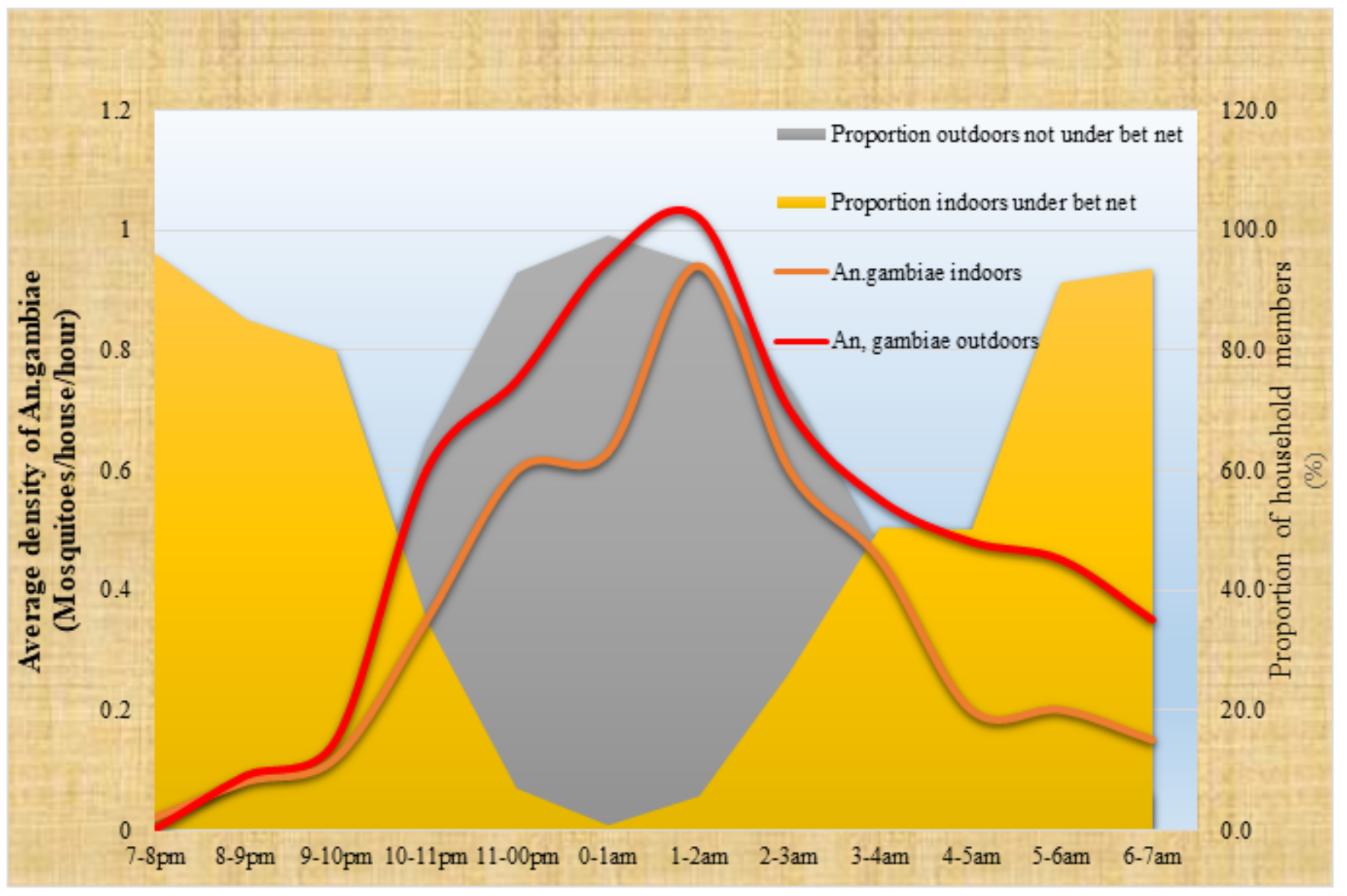

\section{Figure 8}

Illustration of human behavioural activities outside households in the absence of the net and under the net within households in relation to the aggressiveness of An. gambiae mosquitoes, measured at different night time intervals during hot periods. 


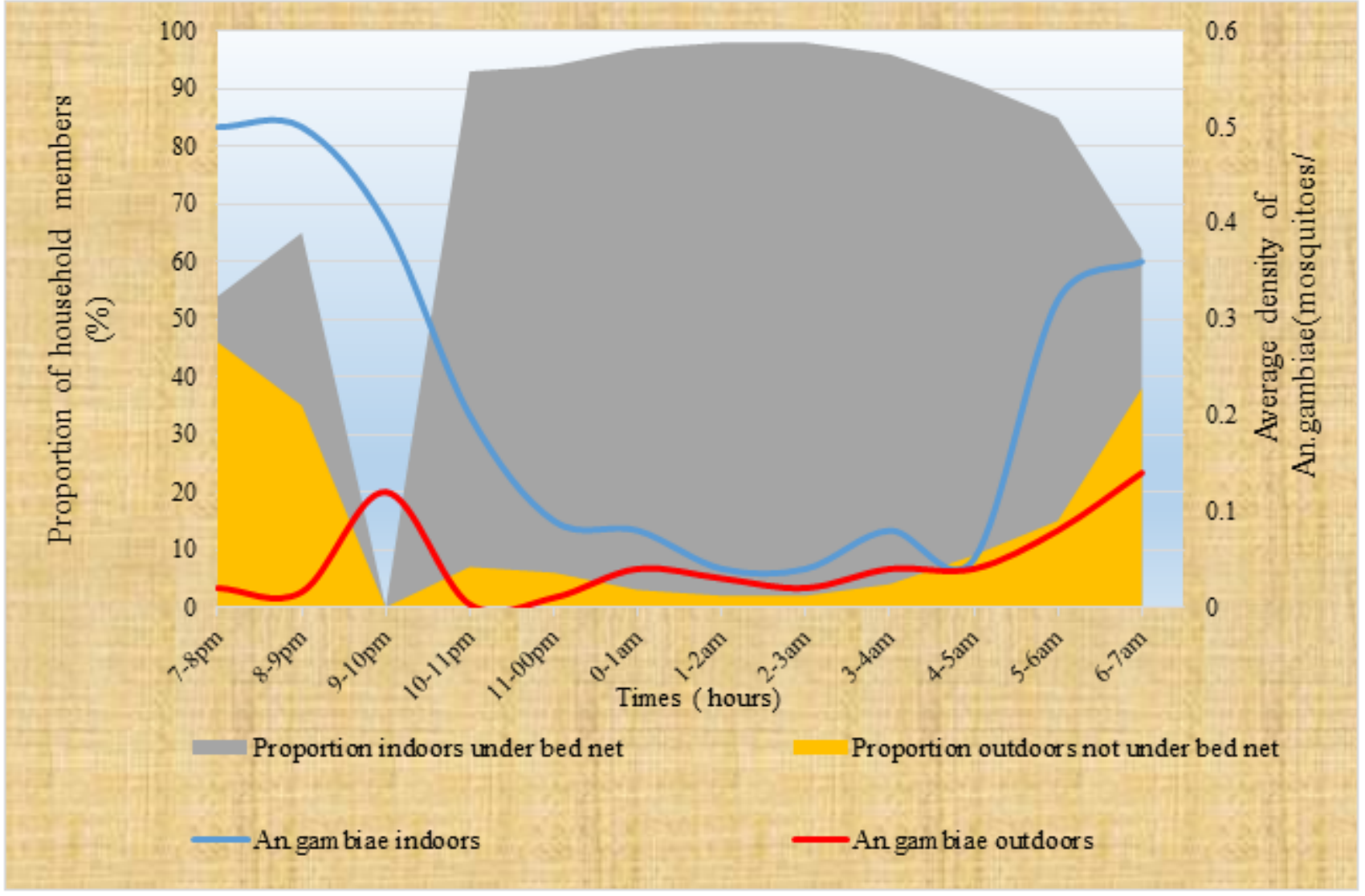

\section{Figure 9}

Illustration of human behavioural activities outside households in the absence of the net and under the net within households in relation to the aggressiveness of An. gambiae mosquitoes, measured at different night time intervals during the harmattan.

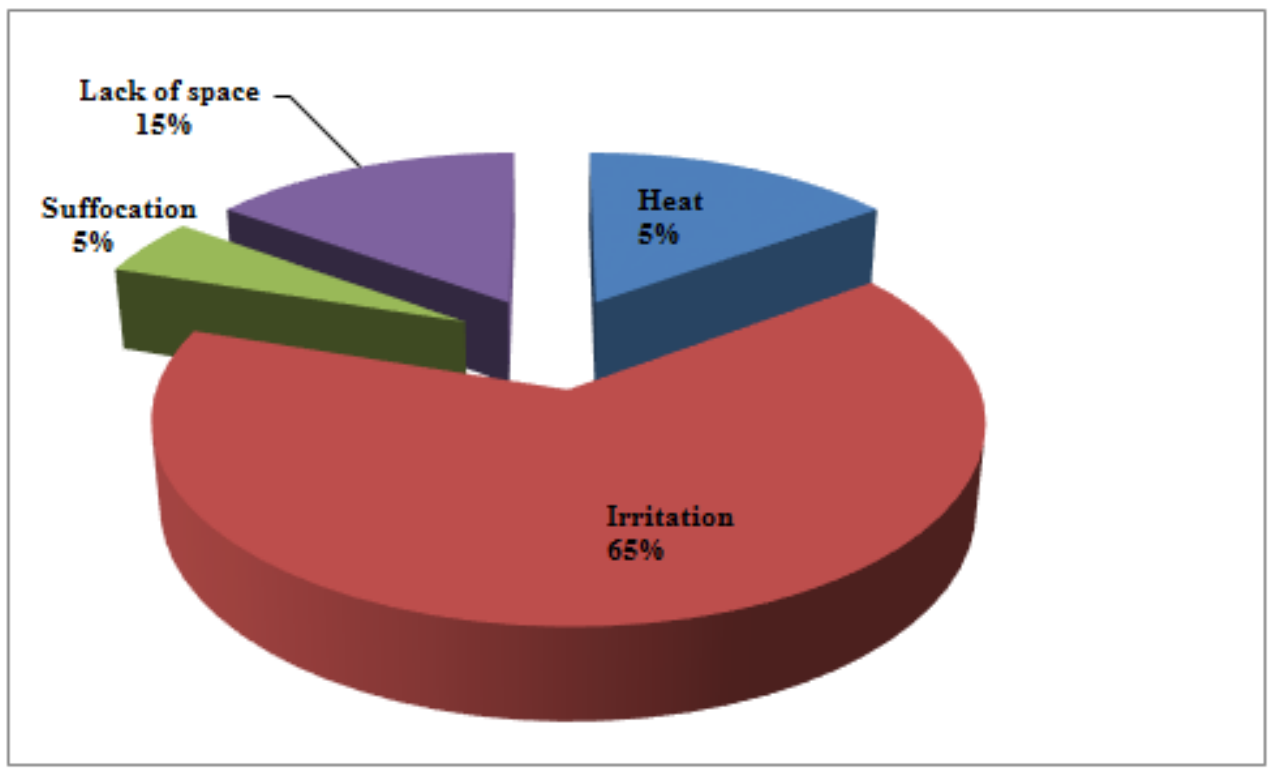

Figure 10

Causes of outdoor biting exposure 